\title{
Long-term outcomes after first-onset arrhythmia in Fontan physiology
}

\author{
Thomas A. Carins, MD, ${ }^{a}$ William Y. Shi, MBBS, ${ }^{a, b, c}$ Ajay J. Iyengar, MBBS, PhD, ${ }^{a, b, c}$ \\ Ashley Nisbet, MBChB, MRCP(UK), PhD, ${ }^{\text {h }}$ Victoria Forsdick, BAppSc Phty (Hons), ${ }^{1}$ \\ Diana Zannino, MSc(Res), ${ }^{\mathrm{c}}$ Thomas Gentles, MBChB, FRACP, \\ Dorothy J. Radford, MBBS, MD, FRACP, ${ }^{\mathrm{h}}$ Robert Justo, MBBS, FRACP, ${ }^{\mathrm{k}}$ \\ David S. Celermajer, MBBS, PhD, DSc, FRACP, ${ }^{\mathrm{e}}$ Andrew Bullock, MBBS, FRACP, \\ David Winlaw, MBBS, MD, FRACS, ${ }^{\mathrm{d}}$ Gavin Wheaton, MBBS, FRACP, ${ }^{\mathrm{f}}$ Leeanne Grigg, MBBS, FRACP, \\ and Yves d'Udekem, MD, $\mathrm{PhD}^{\mathrm{a}, \mathrm{b}, \mathrm{c}}$
}

\begin{abstract}
Objectives: Patients living with a Fontan circulation are prone to develop arrhythmias. However, their prognostic impact has been seldom studied. As such, we aimed to determine the incidence and predictors of arrhythmias after the Fontan procedure and the long-term outcomes after the first onset of arrhythmias.

Methods: Of the 1034 patients who have undergone a Fontan procedure as recorded in the Australian and New Zealand Fontan Registry, we identified those in whom a tachyarrhythmia or bradyarrhythmia developed. We evaluated the incidence and predictors of developing arrhythmias and their prognostic impact on late outcomes.

Results: Arrhythmia developed in 195 patients. Tachyarrhythmia was present in 162 patients, bradyarrhythmia was present in 74 patients, and both forms were present in 41 patients. At 20 years, freedom from any arrhythmia, tachyarrhythmia, and bradyarrhythmia was $66 \%$ (95\% confidence interval [CI], $59-72), 69 \%$ (95\% CI, 62-75), and 85\% (95\% CI, 80-90), respectively. On multivariable analyses, patients with an extracardiac Fontan (hazard ratio [HR], 0.23; $95 \%$ CI, $0.10-0.51 ; P<.001)$ were less likely to develop an arrhythmia, whereas those with left atrial (HR, 3.18; 95\% CI, 1.45-6.95; $P=.004)$ and right atrial (HR, 4.00; 95\% CI, 2.41-6.61; $P<.001)$ isomerism were more likely to have an arrhythmia. After onset of any arrhythmia (tachyarrhythmia or bradyarrhythmia), 10 - and 15 -year survivals were $74 \%(65 \%-83 \%)$ and $70 \%(60 \%-80 \%)$, respectively, and freedom from Fontan failure was 55\% (44\%-64\%) and 44\% (32\%$56 \%$ ), respectively. The development of any arrhythmia (HR, 2.20; $95 \% \mathrm{CI}$, 1-44-3.34; $P<.001$ ), tachyarrhythmia (HR, 2.56; 95\% CI, 1.60-4.11; $P<.001$ ), and bradyarrhythmia (HR, $1.85 ; 95 \% \mathrm{CI}, 1.16-2.95 ; P=.01)$ were all independent predictors of late Fontan failure on multivariable analyses.
\end{abstract}

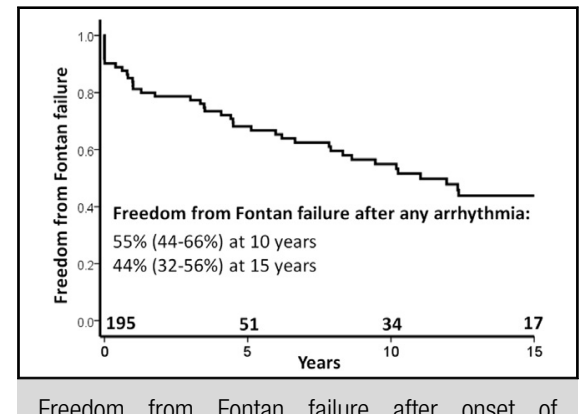

Freedom from Fontan failure after onset of arrhythmia.

\section{Central Message}

The development of an arrhythmia is associated with a heightened risk of subsequent failure of the Fontan circulation. Current treatment strategies prevent Fontan failure in approximately half of these patients at 10 years.

\section{Perspective}

Arrhythmias are associated with an increased risk of failure of the Fontan circulation. Timing of surgery, such as transplantation and Fontan conversion, remains difficult to identify because current medical management (medications, DCCV, and ablation) provides relief to half of patients for 10 years.

See Editorial Commentary page 1364.

\footnotetext{
From the a Department of Cardiac Surgery, The Royal Children's Hospital; 'bepartment of Paediatrics, University of Melbourne; ${ }^{\mathrm{C} T h e}$ Murdoch Childrens Research Institute; ' The Heart Centre for Children, The Children's Hospital at Westmead; ${ }^{\mathrm{e}}$ Department of Cardiology, Royal Prince Alfred Hospital; ${ }_{\mathrm{f}}^{\mathrm{f}}$ Department of Cardiology, Women's and Children's Hospital, Adelaide; ${ }^{\mathrm{g}}$ Green Lane Congenital Cardiac Service, Starship Children's Hospital, Auckland, New Zealand; ${ }^{\mathrm{h}}$ Department of Cardiology, The Prince Charles Hospital, Brisbane; ${ }^{\mathrm{i}}$ Department of Cardiology, Royal Melbourne Hospital, Melbourne; ${ }^{j}$ Paediatric Cardiology, Princess Margaret Hospital for Children, Perth; ${ }^{\mathrm{k}}$ Queensland Paediatric Cardiac Service, Lady Cilento Hospital, Brisbane, Queensland; and ${ }^{\mathrm{l} D e p a r t m e n t}$ of Medicine, The University of Notre Dame, Sydney, Australia.

The Australia and New Zealand Fontan Registry is funded by grants from the National Health and Medical Research Council (Project Grants 1012241, 1047923, and 1065794). The authors acknowledge support provided to the Murdoch Chil-
}

drens Research Institute by the Victorian Government's Operational Infrastructure Support Program

T.A.C. and W.Y.S. are joint first authors.

Read at the 95th Annual Meeting of The American Association for Thoracic Surgery, Seattle, Washington, April 25-29, 2015.

Received for publication April 26, 2015; revisions received July 26, 2016; accepted for publication July 26, 2016.

Address for reprints: Yves d'Udekem, MD, PhD, Department of Cardiac Surgery, The Royal Children's Hospital, Flemington Rd, Parkville, Melbourne, Victoria 3052, Australia (E-mail: yves.dudekem@rch.org.au).

0022-5223/\$36.00

Copyright (C) 2016 by The American Association for Thoracic Surgery

http://dx.doi.org/10.1016/j.jtcvs.2016.07.073 


$$
\begin{aligned}
& \text { Abbreviations and Acronyms } \\
& \begin{aligned}
\text { CI } & =\text { confidence interval } \\
\text { DCCV } & =\text { direct current cardioversion } \\
\text { HR } & =\text { hazard ratio } \\
\text { IQR } & =\text { interquartile range }
\end{aligned}
\end{aligned}
$$

Scanning this QR code will take you to supplemental figures and table for this article. To view the AATS 2015 Webcast, see the URL at the end of the article.

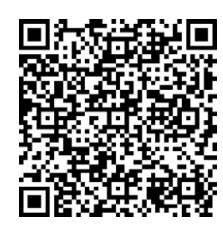

Conclusions: The development of an arrhythmia is associated with a heightened risk of subsequent failure of the Fontan circulation. (J Thorac Cardiovasc Surg 2016;152:1355-63)

Long-term survival after the Fontan procedure has improved, but these patients remain at risk of arrhythmias, thromboembolic events, and failure of their circulation. ${ }^{1-4}$ Arrhythmias have been described to occur in $13 \%$ to $54 \%$ of patients over the course of the first 2 decades after Fontan surgery. ${ }^{1,5,6}$ They seem to predominantly occur in the patients who have undergone the atriopulmonary connection, with arrhythmias occurring as a response to progressive atrial stretch.,

There are limited data on the type of arrhythmias encountered and their prognostic impact on late outcomes. As such, we sought to use the Australian and New Zealand Fontan Registry to evaluate our experience with arrhythmias in patients with a Fontan circulation and determine their prognostic impact on long-term outcomes.

\section{MATERIALS AND METHODS}

The Australian and New Zealand Fontan Registry was commenced in 2008 and includes patients who underwent the Fontan procedure in both countries. All 8 pediatric and 7 adult centers overseeing the care of patients with congenital heart disease in Australia and New Zealand participated in this study.

The clinical characteristics and early and late outcomes of the patients have been reported by d'Udekem and colleagues. ${ }^{1}$ Data for this study were extracted from the Australia and New Zealand Fontan Registry for the patients who consented to the Registry. For those who had not provided consent, data were obtained from hospital databases. ${ }^{1,9}$ Patients who died before discharge after the Fontan procedure and those who underwent Fontan takedown in the same admission were excluded. This study was approved nationally and by the Hospital Research Ethics committees of the participating centers.

Tachyarrhythmias were defined as a documented supraventricular tachycardia, atrial flutter, atrial fibrillation, or intra-atrial reentry tachycardia. Bradyarrhythmias were defined as a documented complete heart block, sinus node dysfunction, or bradycardia (defined as a resting heart rate of $<50$ beats $/ \mathrm{min}$ ). The presence of arrhythmia was determined using cardiologist clinical review documentation and hospital medical documentation. We identified the time point at which an arrhythmia was first recognized and analyzed freedom from late end points.

To determine the prognostic impact of arrhythmia on long-term outcomes, we examined 3 late end points: death, death or cardiac transplantation, and Fontan failure. The composite end point of Fontan failure was defined as death, heart transplantation, Fontan takedown or conversion, protein-losing enteropathy, plastic bronchitis, or New York Heart Association functional class III or IV at follow-up.

Echocardiogram reports were reviewed to assess the onset of a decrease in ventricular function. Because patients were investigated across several centers, no single quantitative measurement of ventricular systolic function could be obtained, and these echocardiographic reports retain a degree of subjectivity. Generally, patients were deemed to have reduced ventricular function if their echocardiogram showed evidence of at least moderate systolic dysfunction on visual assessment. We analyzed the time point at which patients were first found to have reduced ventricular function, because we deemed this to represent an important point in patients' clinical trajectory, which may potentially herald an increased risk of subsequent late events.

\section{Statistical Analysis}

Data were analyzed using SPSS Version 23.0 (IBM Corp, Armonk, $\mathrm{NY}$ ). Continuous variables were compared using the unpaired $t$ test, Wilcoxon signed-rank test, and 1-way analysis of variance. Categoric variables were compared using the Fisher exact and chi-square tests.

The Kaplan-Meier method and log-rank statistic were used. We determined freedom from arrhythmias since the date of the initial Fontan procedure. Separate analyses were performed for any arrhythmia, tachyarrhythmia, and bradyarrhythmia. As such, patients who experienced both a tachyarrhythmia and bradyarrhythmia formed part of both the tachyarrhythmia and bradyarrhythmia subgroup analyses.

In addition, we also determined the freedom from late events from the time of the first onset of an arrhythmia. In these Kaplan-Meier analyses, $\mathrm{t}=0$ referred to the time of the arrhythmia. Again, separate analyses were performed for any arrhythmia, tachyarrhythmia, and bradyarrhythmia.

Multivariable Cox regression was used to determine the independent predictors of developing arrhythmias after the Fontan procedure. The covariates entered into the regression model are shown in Table 1.

To determine the impact of an arrhythmia on long-term outcomes, the time of the first onset of an arrhythmia was inserted into the multivariable Cox regression model as a time-varying covariate, and its associated hazard ratio (HR) was calculated. In essence, patients' follow-up was split into 2 periods: before and after the onset of arrhythmia. As such, the association between the development of an arrhythmia and the subsequent late end points could be established.

\section{RESULTS \\ Occurrence of Arrhythmia}

From 1975 to 2014, a total of 1034 patients were discharged alive after the Fontan procedure across Australia and New Zealand. There were 210 atriopulmonary, 269 lateral tunnel, and 555 extracardiac conduit Fontan variants.

An arrhythmia was present in 195 patients. Of these, tachyarrhythmia was present in 162. These tachyarrhythmias were diagnosed as supraventricular tachycardia in 96 patients, atrial flutter in 34 patients, atrial fibrillation in 17 patients, junctional tachycardia in 10 patients, and ventricular tachycardia in 5 patients. A bradyarrhythmia occurred 
TABLE 1. Description of morphology and demographics by the arrhythmia first encountered

\begin{tabular}{|c|c|c|c|c|c|c|c|}
\hline Variable & $\begin{array}{c}\text { No arrhythmia } \\
\quad(n=839)\end{array}$ & $\begin{array}{c}\text { Tachyarrhythmia } \\
(\mathbf{n}=153)\end{array}$ & $\begin{array}{c}P(\text { none vs } \\
\text { tachyarrhythmia) }\end{array}$ & $\begin{array}{c}\text { Bradyarrhythmia } \\
(\mathrm{n}=\mathbf{4 2})\end{array}$ & $\begin{array}{c}P \text { (none vs } \\
\text { bradyarrhythmia) }\end{array}$ & $\begin{array}{l}P \text { (tachyarrhythmia } \\
\text { vs bradyarrhythmia) }\end{array}$ & $\begin{array}{l}P \text { value } \\
\text { (overall) }\end{array}$ \\
\hline Male & $482(57)$ & $88(58)$ & $>.99$ & $27(64)$ & .43 & .48 & .68 \\
\hline $\begin{array}{l}\text { Age at Fontan, y, } \\
\text { median (IQR) }\end{array}$ & $5(3-7)$ & $6(3-10)$ & .003 & $5(4-6)$ & .47 & .24 & .47 \\
\hline \multicolumn{8}{|l|}{ Era } \\
\hline Pre-1995 & $258(31)$ & $111(73)$ & $<.001$ & $13(31)$ & $>.99$ & $<.001$ & $<.001$ \\
\hline $1996-2005$ & $353(42)$ & $27(18)$ & $<.001$ & $23(55)$ & .002 & $<.001$ & $<.001$ \\
\hline 2005-2014 & $225(27)$ & $15(10)$ & $<.001$ & $6(14)$ & .074 & .41 & $<.001$ \\
\hline Prior BCPC & $521(62)$ & $38(25)$ & $<.001$ & $20(48)$ & .073 & .0071 & $<.001$ \\
\hline Prior PA banding & $232(28)$ & $30(20)$ & .046 & $16(38)$ & .16 & .023 & .029 \\
\hline Prior aortic arch repair & $39(5)$ & $2(1)$ & .074 & $5(12)$ & .053 & .0056 & .01 \\
\hline $\begin{array}{l}\text { Prolonged pleural } \\
\text { effusions }\end{array}$ & $45(5)$ & $12(8)$ & .25 & $4(10)$ & .29 & .75 & .29 \\
\hline \multicolumn{8}{|l|}{ Type of Fontan } \\
\hline AP & $111(13)$ & $88(58)$ & $<.001$ & $11(26)$ & .035 & $<.001$ & $<.001$ \\
\hline LT & $224(27)$ & $32(21)$ & .16 & $13(31)$ & .59 & .21 & .25 \\
\hline ECC & $504(60)$ & $33(22)$ & $<.001$ & $18(43)$ & .036 & .0092 & $<.001$ \\
\hline \multicolumn{8}{|l|}{ Primary diagnosis } \\
\hline Tricuspid atresia & $195(23)$ & $41(27)$ & .35 & $11(26)$ & .71 & $>.99$ & .60 \\
\hline DILV & $148(18)$ & $31(20)$ & .43 & $12(29)$ & .098 & .29 & .17 \\
\hline DORV & $140(17)$ & $30(20)$ & .41 & $4(10)$ & .29 & .17 & .29 \\
\hline CAVC & $83(10)$ & $18(12)$ & .47 & $1(2)$ & .17 & .081 & .20 \\
\hline HLHS & $82(10)$ & $3(2)$ & $<.001$ & $5(12)$ & .60 & .013 & .005 \\
\hline Pulmonary atresia & $88(10)$ & $11(7)$ & .24 & $2(5)$ & .30 & .74 & .24 \\
\hline TGA & $40(5)$ & $3(2)$ & .13 & $0(0)$ & .25 & $>.99$ & .11 \\
\hline ccTGA & $39(5)$ & $11(7)$ & .22 & $5(12)$ & .053 & .34 & .066 \\
\hline Other & $24(3)$ & $5(3)$ & .79 & $2(5)$ & .35 & .64 & .76 \\
\hline $\begin{array}{l}\text { RV dominant } \\
\text { morphology }\end{array}$ & $244(29)$ & $38(25)$ & .33 & $12(29)$ & $>.99$ & 69 & .56 \\
\hline \multicolumn{8}{|l|}{ Isomerism } \\
\hline None & $791(94)$ & $130(85)$ & $<.001$ & $39(93)$ & .73 & .30 & .002 \\
\hline LA isomerism & $19(2)$ & $6(4)$ & .26 & $1(2)$ & .082 & $>.99$ & .48 \\
\hline $\mathrm{RA}$ isomerism & $29(3)$ & $17(11)$ & $<.001$ & $2(5)$ & .66 & .38 & .002 \\
\hline Dextrocardia & $68(8)$ & $19(12)$ & .088 & $1(2)$ & .24 & .082 & .074 \\
\hline Oxygen saturation $(\%)$ & $82(78-86)$ & $81(75-86)$ & .20 & $83(80-85)$ & .93 & .55 & .33 \\
\hline $\begin{array}{l}\text { Pulmonary artery } \\
\text { pressure }(\mathrm{mm} \mathrm{Hg}) \\
\text { median }(\mathrm{IQR})\end{array}$ & $11(10-13)$ & $12(10-14)$ & .12 & $12(11-14)$ & .054 & .50 & .063 \\
\hline $\begin{array}{l}\text { Age at first-onset } \\
\text { arrhythmia (y), } \\
\text { median (IQR) }\end{array}$ & - & $21(15-31)$ & & $7(5-10)$ & & $<.001$ & $<.001$ \\
\hline $\begin{array}{l}\text { Age at most recent } \\
\text { follow-up (y), } \\
\text { median (IQR) }\end{array}$ & $14(10-18)$ & $26(18-33)$ & $<.001$ & $17(12-21)$ & .003 & $<.001$ & $<.001$ \\
\hline
\end{tabular}

$\overline{I Q R}$, Interquartile range; $B C P C$, bidirectional cavopulmonary connection; $P A$, pulmonary artery; $A P$, atriopulmonary; $L T$, lateral tunnel; $E C C$, extracardiac conduit; $D I L V$, doubleinlet left ventricle; $D O R V$, double-outlet right ventricle; $C A V C$, common atrioventricular canal; $H L H S$, hypoplastic left heart syndrome; $T G A$, transposition of the great arteries; $c c T G A$, congenital-corrected transposition of the great arteries; $R V$, right ventricle; $L A$, left atrium; $R A$, right atrium.

in 74 patients. These were diagnosed as complete heart block in 28 patients, sick sinus syndrome in 26 patients, and bradycardia in 20 patients. In 41 patients, both a tachyarrhythmia and bradyarrhythmia were encountered.

Among the 195 patients who experienced an arrhythmia, the arrhythmia first encountered was a tachyarrhythmia in 153 and a bradyarrhythmia in 42. The clinical characteristics of the patients compared by the type of arrhythmia first encountered are shown in Table 1.

At 20 years, freedom from any arrhythmia, tachyarrhythmia, and bradyarrhythmia was $66 \%$ (95\% confidence interval [CI], 59-72), 69\% (95\% CI, 62-75), and 85\% (95\% CI, 80-90), respectively. Kaplan-Meier estimates of freedom from arrhythmia are presented in Figure 1. 


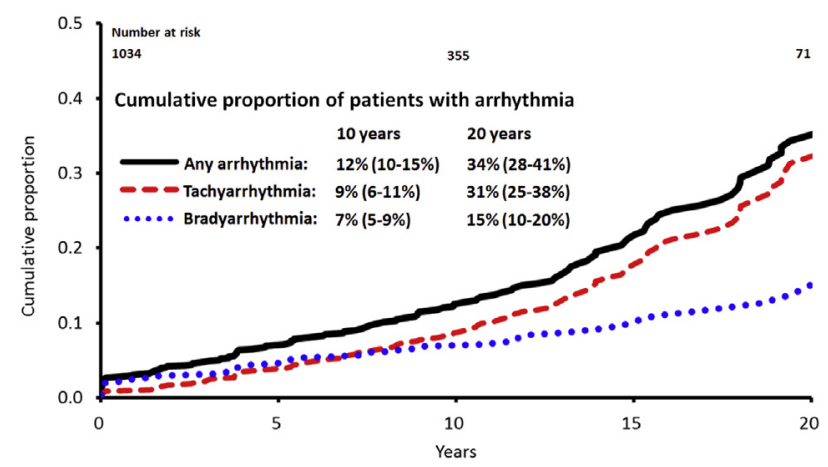

FIGURE 1. Cumulative proportion of arrhythmias encountered after the Fontan procedure.

Independent predictors of developing an arrhythmia are presented in Table 2. Patients with an extracardiac Fontan (HR, $0.23 ; 95 \%$ CI, 0.10-0.51; $P<.001$ ) were less likely to develop an arrhythmia compared with those with an atriopulmonary connection, whereas those with left atrial (HR, 3.18; 95\% CI, 1.45-6.95; $P=.004$ ) and right atrial (HR, 4.00; 95\% CI, 2.41-6.61; $P<.001$ ) isomerism were more likely to have an arrhythmia.

\section{Outcomes After First-Onset Arrhythmia}

Of the 195 patients with an arrhythmia on follow-up, the first arrhythmia was a tachyarrhythmia in 153 patients and a bradyarrhythmia in 42 patients. After the first onset of an arrhythmia, 33 patients died, 12 patients underwent heart transplantation, 30 patients underwent Fontan conversion to an extracardiac conduit, 3 patients underwent Fontan takedown, 12 patients developed protein-losing enteropathy, and 25 patients developed New York Heart Association class III or IV symptoms. In total, 84 patients reached the composite end point of Fontan failure. The

TABLE 2. Independent predictors of developing arrhythmia postFontan procedure

\begin{tabular}{lcccr}
\hline \multicolumn{1}{c}{ Variable } & HR & $\begin{array}{c}\text { 95\% CI } \\
\text { lower }\end{array}$ & $\begin{array}{c}\mathbf{9 5} \% \mathbf{C I} \\
\text { upper }\end{array}$ & $\begin{array}{c}\boldsymbol{P} \\
\text { value }\end{array}$ \\
\hline Any arrhythmia & & & & \\
ECC Fontan (vs AP)* & 0.23 & 0.10 & 0.51 & $<.001$ \\
LT Fontan (vs AP) & 0.60 & 0.36 & 1.01 & .055 \\
LA isomerism & 3.18 & 1.45 & 6.95 & .004 \\
RA isomerism & 4.00 & 2.41 & 6.61 & $<.001$ \\
Tachycardia & & & & \\
ECC Fontan (vs AP) $\dagger$ & 0.34 & 0.13 & 0.92 & .033 \\
LA isomerism (vs none) & 4.17 & 1.77 & 9.79 & .001 \\
RA isomerism (vs none) & 4.61 & 2.70 & 7.86 & $<.001$ \\
$\quad$ Dextrocardia & 1.64 & 0.99 & 2.70 & .054 \\
Bradycardia & & & & \\
ECC Fontan (vs AP) $\ddagger$ & 0.06 & 0.02 & 0.20 & $<.001$ \\
LT Fontan (vs AP) & 0.23 & 0.09 & 0.58 & .002 \\
\hline
\end{tabular}

$H R$, Hazard ratio; $C I$, confidence interval; $E C C$, extracardiac conduit; $A P$, atriopulmonary; $L T$, lateral tunnel; $L A$, left atrium; $R A$, right atrium. *ECC versus $\mathrm{LT}$ (after exclusion of AP): odds ratio [OR], $0.47 ;(95 \% \mathrm{CI}, 0.25-0.87 ; P=.016)$. † $† C C$ versus LT (after exclusion of AP): OR, 0.60 ; $(95 \%$ CI, $0.22-1.67 ; P=.33)$ ) †्ECC versus LT (after exclusion of AP): OR, 0.26; (95\% CI, $0.12-0.58 ; P=.001)$.
TABLE 3. Freedom from late clinical events after first onset of arrhythmia

\begin{tabular}{lcc}
\hline & \multicolumn{2}{c}{ Kaplan-Meier estimate, freedom from event } \\
\cline { 2 - 3 } Event & $\mathbf{1 0} \mathbf{y}$ & $\mathbf{1 5} \mathbf{y}$ \\
\hline Freedom from event after developing any arrhythmia \\
Death & $74 \%(65 \%-83 \%)$ & $70 \%(60 \%-80 \%)$ \\
Death/transplantation & $68 \%(58 \%-78 \%)$ & $63 \%(52 \%-74 \%)$ \\
Fontan failure & $55 \%(44 \%-66 \%)$ & $44 \%(32 \%-56 \%)$ \\
Freedom from event after developing tachycardia & \\
Death & $67 \%(54 \%-79 \%)$ & $64 \%(51 \%-77 \%)$ \\
Death/transplantation & $61 \%(48 \%-74 \%)$ & $56 \%(42 \%-69 \%)$ \\
Fontan failure & $43 \%(29 \%-57 \%)$ & $34 \%(21 \%-47 \%)$ \\
Freedom from event after developing bradycardia & \\
Death & $84 \%(74 \%-93 \%)$ & $81 \%(71 \%-91 \%)$ \\
Death/transplantation & $75 \%(64 \%-86 \%)$ & $72 \%(60 \%-84 \%)$ \\
Fontan failure & $59 \%(46 \%-72 \%)$ & $49 \%(34 \%-63 \%)$ \\
\hline
\end{tabular}

Kaplan-Meier estimates of freedom from late events after the first onset of an arrhythmia are presented in Table 3 and Figure 2. A competing events figure displaying the cumulative proportion of patients alive, dead, or who have undergone Fontan takedown is presented in Figure 3.

After the onset of any arrhythmia, 10-year freedom from Fontan failure for patients with an atriopulmonary, lateral tunnel, and extracardiac conduit Fontan variants was 51\% (95\% CI, 36-66), 54\% (95\% CI, 31-76), and 67\% (95\% CI, 45-89), respectively, and these rates were comparable $(P=.35)$.

The results of multivariable Cox regression using time of arrhythmia onset as a time-varying covariate are shown in Table 4. Any arrhythmia, tachyarrhythmia, and bradyarrhythmia were all independently associated with the end points of death/transplantation and Fontan failure. The association between arrhythmia and survival was not statistically significant.

Independent predictors of late outcomes (with arrhythmia used as a time-varying covariate) after the Fontan procedure are displayed in Table E1. Freedom from Fontan failure stratified by type of first-encountered arrhythmia and type of initial Fontan is presented in Figure E1 and Figure E2, respectively.

\section{Tachyarrhythmias}

Medical management was observed to be the most common initial treatment for tachyarrhythmias. Of the $162 \mathrm{pa}-$ tients with tachyarrhythmias, $140(86 \%)$ had been prescribed at least 1 antiarrhythmic medication. Most patients were prescribed $1(38 / 162,23 \%), 2(34 / 162,21 \%)$, $3(30 / 162,19 \%)$, or more than $3(38 / 162,23 \%)$ types of medications. Of the 380 antiarrhythmic drugs prescribed in the 140 patients, class 3 medications were the most commonly prescribed $(156 / 380,41 \%)$ followed by class 5 $(119 / 380,31 \%)$, class $2(55 / 380,14 \%)$, class $1(25 / 380$, $7 \%)$, and class $4(25 / 380,7 \%)$ medications. 

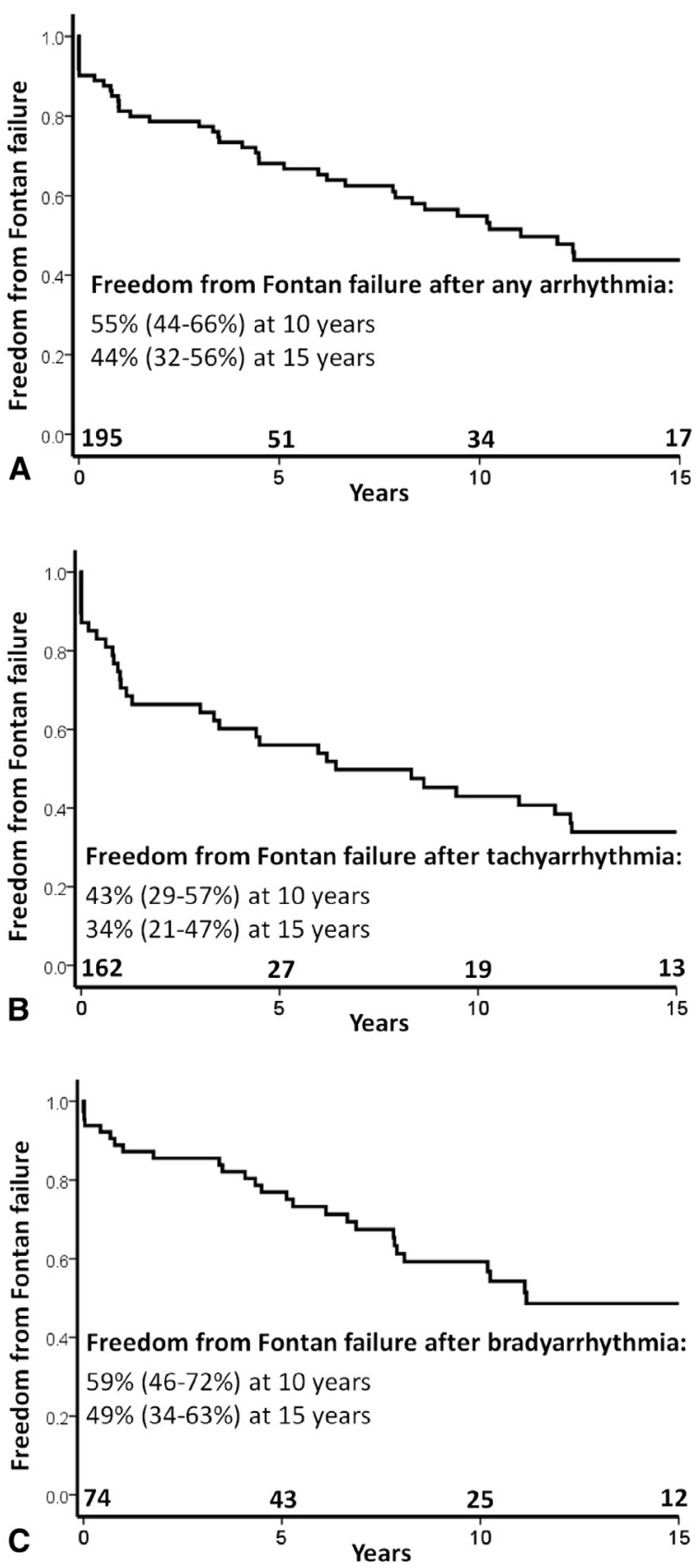

FIGURE 2. Freedom from Fontan failure after onset of (A) any arrhythmia, (B) tachyarrhythmia, and (C) bradyarrhythmia.

A single episode of tachyarrhythmia was observed in 101 patients $(62 \%)$, with no recurrence after a median follow-up of 7.6 years (interquartile range [IQR], 4-13; range, 0-33). Those who experienced a single versus multiple $(\geq 1)$ episodes of tachyarrhythmia showed comparable freedom from Fontan failure (single: $34 \%$ [14\%-50\%] vs multiple: $33 \%[15 \%-52 \%], P=.44)$ at 15 years.

Fourteen patients $(9 \%)$ experienced more than 3 symptomatic tachyarrhythmia episodes. Direct current cardioversion (DCCV) was required in $81(50 \%)$ of the 162 patients

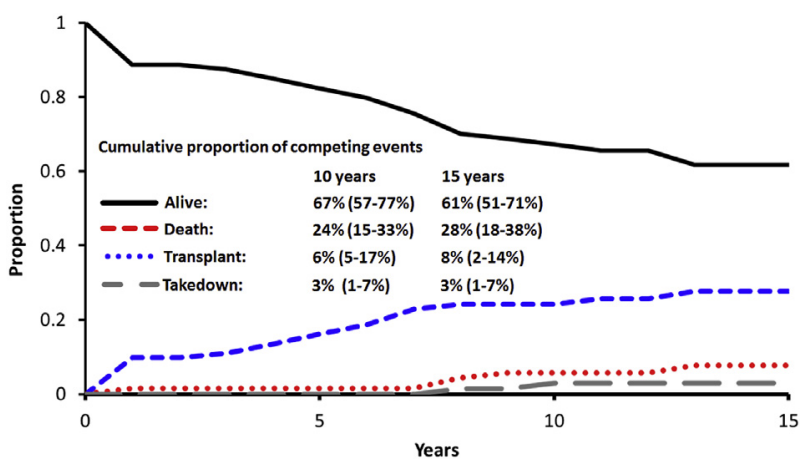

FIGURE 3. Cumulative proportion of patients experiencing competing events after the onset of any arrhythmia.

with tachyarrhythmias at a median of 5 (IQR, 2-11; range, $0-27$ ) years after the first onset of arrhythmia, with a repeat DCCV being required in 49 patients $(60 \%)$. Patients required a median of 2 DCCVs (IQR, 1-4; range, 1-22). The median time between the first and the second DCCV was 2 years (IQR, 1-4; range, 0-25).

A radiofrequency ablation was performed in 55 (34\%) of the 162 patients with tachyarrhythmias. Patients with an ablation had their first onset of tachyarrhythmia at a median of 7 years (IQR, 3-13; range 0-27) before their ablation and had undergone a median of 2 DCCVs (IQR, 2-5; range, 022) before ablation.

The 10- and 20-year freedom from ablation after the onset of a tachyarrhythmias were $70 \%(95 \% \mathrm{CI}, 61-78)$ and $48 \%$ (95\% CI, 36-61), respectively. After an ablation, a further DCCV was required in 19 patients (35\%). After an ablation, 6 patients underwent a Fontan conversion to an extracardiac conduit at a median of 1 year (IQR, 1-7; range, 0.2-18 years). After an initial ablation procedure, freedom from Fontan failure at 5 and 10 years was $62 \%(95 \% \mathrm{CI}$, 48-77) and 50\% (95\% CI, 33-67), respectively.

Among patients with tachyarrhythmias, decreased ventricular systolic function was observed in 69 patients

TABLE 4. Impact of arrhythmia (as a time-varying covariate) on late outcomes: Multivariable Cox proportional hazards regression

\begin{tabular}{|c|c|c|c|c|}
\hline Event & HR & $\begin{array}{c}95 \% \text { CI } \\
\text { lower }\end{array}$ & $\begin{array}{c}95 \% \text { CI } \\
\text { upper }\end{array}$ & $P$ value \\
\hline \multicolumn{5}{|c|}{ Risk of event after developing any arrhythmia } \\
\hline Death & 1.53 & 0.85 & 2.76 & .16 \\
\hline Death/transplantation & 1.76 & 1.02 & 3.02 & .042 \\
\hline Fontan failure & 2.20 & 1.44 & 3.34 & $<.001$ \\
\hline \multicolumn{5}{|c|}{ Risk of event after developing tachycardia } \\
\hline Death & 1.65 & 0.86 & 3.18 & .13 \\
\hline Death/transplantation & 1.87 & 1.02 & 3.45 & .043 \\
\hline Fontan failure & 2.56 & 1.60 & 4.11 & $<.001$ \\
\hline \multicolumn{5}{|c|}{ Risk of event after developing bradycardia } \\
\hline Death & 1.20 & 0.62 & 2.30 & .59 \\
\hline Death/transplantation & 1.81 & 1.04 & 3.15 & .037 \\
\hline Fontan failure & 1.85 & 1.16 & 2.95 & .010 \\
\hline
\end{tabular}


$(69 / 162,43 \%)$. After the onset of tachyarrhythmia, freedom from decreased ventricular function at 5,10 , and 15 years was $72 \%(95 \% \mathrm{CI}, 64-79), 58 \%$ (95\% CI, 49-67), and $38 \%$ (95\% CI, 27-50), respectively.

\section{Bradyarrhythmias}

A pacemaker was implanted in 66 of the 74 patients $(89 \%)$ with bradyarrhythmias. Of these, 24 were for sick sinus syndrome $(36 \%), 24$ were for complete heart block $(36 \%)$, and $18(27 \%)$ were for isolated bradycardia $(31 \%)$. After the onset of a bradyarrhythmia, 31 patients were subsequently found to have reduced ventricular function. Freedom from decreased ventricular function at 5, 10, and 15 years was $69 \%$ (95\% CI, 58-80), 63\% (95\% CI, 50 75 ), and $46 \%$ (95\% CI, 30-61), respectively.

\section{DISCUSSION}

Despite the high prevalence of arrhythmias after Fontan surgery, data are lacking on the clinical outcomes of these patients after the first onset of arrhythmias. Also, many of the previous publications have quoted the incidence of arrhythmias without distinguishing the difference between tachyarrhythmias and bradyarrhythmias. ${ }^{10-12}$

There is concern that the onset of an arrhythmia is the first sign of deterioration of the Fontan circulation. Ascertaining how true this hypothesis is will help guide therapy in these patients and in particular help to optimize the timing of interventions such as the Fontan conversion. The recently commenced Australia and New Zealand Fontan Registry gave us the unique opportunity to investigate these clinical outcomes after arrhythmias in patients with a Fontan circulation. ${ }^{9}$

We found atriopulmonary Fontan, atrial isomerism, and dextrocardia to be predictors of developing arrhythmias, and these are consistent with those previously reported by our group. ${ }^{1}$ Of note, patients with the extracardiac conduit variant were less likely to experience an arrhythmia compared with those with an atriopulmonary connection. In patients with an atriopulmonary connection, referral for Fontan conversion should be considered relatively early because it been shown to be more effective. ${ }^{13}$

Survival after the onset of an arrhythmia was surprisingly good with $67 \%$ and $84 \%$ of patients alive at 10 years after the onset of a tachyarrhythmia and bradyarrhythmia, respectively. There was no association between occurrence of arrhythmia and survival. Previously, we had suspected that the onset of an arrhythmia would be associated with a rapid decline in survival. Nevertheless, the onset of an arrhythmia is associated with a substantial burden of late adverse events with approximately half of patients experiencing failure of the Fontan circulation within 10 years. On multivariable analyses, patients with arrhythmias had a higher risk of the composite end point of death/transplantation and of Fontan failure than those without arrhythmias.
Freedom from Fontan failure was similar after onset of an arrhythmias among the various types of Fontan techniques. One may have expected that outcomes would have been worse in patients with an atriopulmonary connection, who are known to have dilated atrial chambers. Even the need for DCCV did not indicate as rapid a deterioration as perhaps expected, with approximately half of the patients who had an initial DCCV not requiring a second cardioversion for a median of 2 years. In our experience, ablation therapy was reasonably effective, with $50 \%$ of the patients being free from Fontan failure after 10 years. Therefore, ablation therapy should be considered when multiple cardioversions are required.

In this study, approximately $40 \%$ of patients with a tachyarrhythmia or bradyarrhythmia were found to have reduced ventricular function at 10 years after onset of the arrhythmia. Although the assessment of ventricular function in this study was clearly subjective, we nonetheless believe that these findings suggest that the onset of an arrhythmia is associated with a progressive deterioration in cardiac function. After the first onset of an arrhythmia, close surveillance of ventricular systolic function is required.

\section{Study Limitations}

The study is limited by its retrospective nature. Depending on the degree of follow-up, arrhythmic events may not have been detected. Indeed, without the presence of ambulatory rhythm monitoring, arrhythmias may have remained undetected. Nevertheless, our study shows the influence of clinically manifest arrhythmias on long-term outcomes. Ventricular function data were not collected in a systematic fashion, which negated our ability to perform longitudinal data analyses. In addition, the relatively contemporaneous shifts in surgical practice among the centers limit the ability to analyze the impact of surgical era, follow-up duration, and surgical technique despite the use of multivariable analyses.

\section{CONCLUSIONS}

After the first onset of arrhythmia, patients with a Fontan circulation are at increased risk of late Fontan failure.

\section{Webcast}

You can watch a Webcast of this AATS meeting presentation by going to: http://webcast.aats.org/2015/Video/ Monday/04-27-15_6A_1500_Carins.mp4.

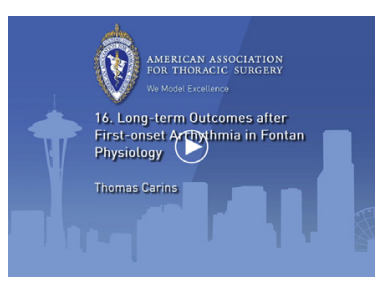




\section{Conflict of Interest Statement}

W.Y.S. is supported by the Royal Australasian College of Surgeons Foundation for Surgery Peter King/Heart Foundation Research Scholarship in addition to the University of Melbourne Viola Edith Reid and the RG and AU Meade Scholarships. A.B. reports consulting fees from Actelion. Y.d'U. is a National Health and Medical Research Council Clinician Practitioner Fellow (1082186). The Victorian Government's Operational Infrastructure Support Program supported this research project. All other authors have nothing to disclose with regard to commercial support.

The authors thank their research assistants, Dr Karin du Plessis, Ingrid King, Dr Aneta Kotevski, Janina Chapman, Charlotte Verrall, and Megan Upjohn, for assistance in the creation and maintenance of the Registry and to Belinda Bortone for administrative support.

\section{References}

1. d'Udekem Y, Iyengar AJ, Galati JC, Forsdick V, Weintraub RG, Wheaton GR, et al. Redefining expectations of long-term survival after the Fontan procedure. Circulation. 2014;130(11 Suppl 1):S32-8.

2. Khairy P, Poirier N, Mercier L-A. Univentricular heart. Circulation. 2007;115: 800-12.

3. de Leval MR, Deanfield JE. Four decades of Fontan palliation. Nat Rev Cardiol. 2010;7:520-7.

4. Iyengar AJ, Winlaw DS, Galati JC, Wheaton GR, Gentles TL, Grigg LE, et al; Australia and New Zealand Fontan Registry. The extracardiac conduit Fontan procedure in Australia and New Zealand: hypoplastic left heart syndrome predicts worse early and late outcomes. Eur J Cardiothorac Surg. 2014;46: 465-73.

5. d'Udekem Y, Iyengar AJ, Cochrane AD, Grigg LE, Ramsay JM, Wheaton GR, et al. The Fontan procedure: contemporary techniques have improved longterm outcomes. Circulation. 2007;116:I157-64.

6. Weipert J, Noebauer C, Schreiber C, Kostolny M, Zrenner B, Wacker A, et al. Occurrence and management of atrial arrhythmia after long-term Fontan circulation. J Thorac Cardiovasc Surg. 2004;127:457-64.

7. Wong T, Davlouros PA, Li W, Millington-Sanders C, Francis DP, Gatzoulis MA. Mechano-electrical interaction late after Fontan operation: relation between Pwave duration and dispersion, right atrial size, and atrial arrhythmias. Circulation. 2004;109:2319-25.

8. Shirai LK, Rosenthal DN, Reitz BA, Robbins RC, Dubin AM. Arrhythmias and thromboembolic complications after the extracardiac Fontan operation. J Thorac Cardiovasc Surg. 1998;115:499-505.

9. Iyengar AJ, Winlaw DS, Galati JC, Gentles TL, Weintraub RG, Justo RN, et al. The Australia and New Zealand Fontan Registry: description and initial results from the first population-based Fontan registry. Intern Med J. 2014;44:148-55.

10. Idorn L, Juul K, Jensen AS, Hanel B, Nielsen KG, Andersen H, et al. Arrhythmia and exercise intolerance in Fontan patients: current status and future burden. Int $J$ Cardiol. 2013;168:1458-65.

11. Celik M, Sarıtaş B, Tatar T, Ozkan M, Akay T, Aşlamacı S. Risk factors for postoperative arrhythmia in patients with physiologic univentricular hearts undergoing Fontan procedure. Anadolu Kardiyol Derg. 2012;12:347-51.

12. Hakacova N, Lakomy M, Kovacikova L. Arrhythmias after Fontan operation: comparison of lateral tunnel and extracardiac conduit. J Electrocardiol. 2008; 41:173-7.

13. Poh CL, Cochrane A, Galati JC, Bullock A, Celermajer DS, Gentles T, et al. Tenyear outcomes of Fontan conversion in Australia and New Zealand demonstrate the superiority of a strategy of early conversion. Eur J Cardiothorac Surg. 2016; 49:530-5.

Key Words: Fontan procedure, arrhythmia, long-term outcomes, Fontan failure

\section{Discussion}

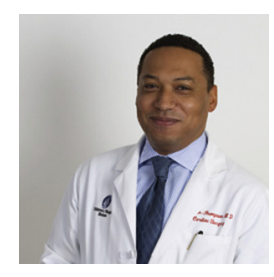

Dr F. Fynn-Thompson (Boston, Mass). I want to congratulate Dr Carins for an excellent and clear presentation, and I want to commend our colleagues in Australia and New Zealand for creating this Fontan registry, which I believe is the largest of its kind and which with each analysis is advancing our knowledge of contemporary Fontan outcomes.

In your study, you identified arrhythmias in approximately $20 \%$ of patients, but the overall survival was similar after the onset of tachyarrhythmia or bradyarrhythmia among the various types of Fontans. Your analysis identified the first episode of an arrhythmia as a tipping point that is often followed by progressive deterioration in systemic ventricular function. Although medical management, including direct cardioversion, could mitigate the clinical sequelae of these symptoms as related to the arrhythmias, the ventricular function did not appear to recover in most of those patients, and those patients were less likely to be alive with Fontan circulation at 20 years. Some $40 \%$ of those patients with a decrease in ventricular function had a major adverse event within 5 years. This is an important study and has significant potential implications for how we manage and expectantly treat arrhythmias in our Fontan cases.

I want to point out 2 important characteristics of this study population and registry that you did not present but were available in your article, and these are different from previous reported case series, including the Pediatric Heart Network (PHN) Fontan Cross-Sectional Study, looking at long-term Fontan outcomes.

The median age for the Fontan operation in your patient population was approximately 5 years. It was 3.3 years in the PHN study and 2.3 years in the study just presented from the group at Children's Hospital of Philadelphia (CHOP). Also, the morphologic characteristics of the group are different in that only $8 \%$ of your registry population had hypoplastic left heart syndrome versus $20 \%$ in the PHN study and as high as 50\% again in the just presented CHOP study.

It has been suggested by a number of studies, including one from our center, looking at cohorts of earlier era Fontan cases that heart failure and sudden death presumed to be from arrhythmias were more likely in patients with single right ventricle morphology, particularly those with hypoplastic left heart syndrome.

Can you provide us with some insight as to the skewed demographic and morphologic makeup of your Fontan population, the fewer number of hypoplasts, and if you think that has any impact on your analysis of the rate of arrhythmias and long-term results? 


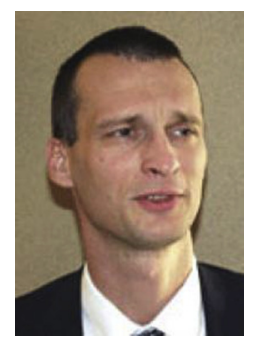

Dr d'Udekem. So you want to know how much the skewing of our population compared with the previous series is affecting outcomes, and the real answer is we don't know, obviously. There are a few interesting things that we're learning today. The previous talk was interesting in showing that in terms of survival at 20 years, even Philadelphia cannot prove that having a single right ventricle is worse than having a single left ventricle.

Now, you're saying that in terms of sudden death, our incidence may be less than other groups because our population is skewed. I would contend that most of us here do not know the cause of death and failure in Fontan populations. The only 2 articles that have described the cause of death that I know of is the famous Khairy article saying that one third of the patients died of sudden death, and we had the same conclusion in a study that we did in Melbourne in 2005. I went back, as a surgeon, to look at all the files of the patients who died. The type of sudden death I encountered was an atriopulmonary connection Fontan in someone with complete heart block who died suddenly while he was swimming, not really an unexpected death. The only 2 sudden deaths I could find were in patients with pulmonary atresia intact septum and right ventricle-dependent coronary circulations. I think the idea that these patients die suddenly of arrhythmia is a myth, but we have to do more exploration.

Dr Fynn-Thompson. My second and final question relates to a central question, much like Dr Kirklin's question, which I think is a focus in all our minds, I expect, and that is, what are we to do with this information? Your results are excellent, 20-year survivals even after first onset of tachyarrhythmia and bradyarrhythmia are $72 \%$ and $81 \%$, respectively. This is obviously pretty good and better than expected.

As you're aware, there is a growing enthusiasm in our field for staged biventricular repair rather than single-ventricle palliation. A lot of that enthusiasm is rooted in the old, historical results of Fontan outcomes. So my question is, how has this information affected your practice? Do you think results like this should have us reconsider how we view the Fontan operation, how we counsel our patients and families?

Dr d'Udekem. I have to confess that when I directed the study at the start, I had a personal agenda. My agenda was to say I believe that when these patients start to have arrhythmia, their health is going to decrease in a matter of years, and we have to start performing reoperations in them. I wanted to do a conversion as soon as they had arrhythmia and bring the arguments for that. I thought that ablation therapy was absolutely hopeless, we should stop doing it, and we should do conversion in all of these patients. I found out that the results were better than I expected. So to answer your question, I'm more confused now than before the study. All we need to do is to find out at what time we should reintervene in these patients. Now it's even more difficult because, yes, they have symptomatic relief for quite a while.

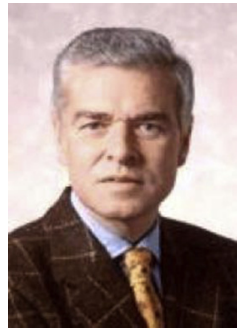

Dr G. Stellin (Padua, Italy). Some of the patients with a single-ventricle morphology in the context of the heterotaxy syndrome will develop some bradyarrhythmia. I'm talking about the polysplenia syndrome in which there is not a well-defined sinus node. I wonder if you found a correlation between early onset of arrhythmias and heterotaxy syndrome?

Dr d'Udekem. We did not find any predictive value of this parameter in our previous analysis. We didn't repeat the risk prediction analysis for tachyarrhythmia or bradyarrhythmia in this analysis because the goal was mainly to identify late outcomes after the onset of arrhythmia. But it's a good point, because now that we have identified bradyarrhythmia, that's a study that we should do.

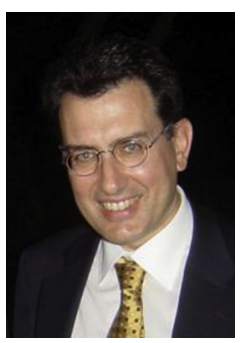

Dr G. Sarris (Athens, Greece). It was not clear to me from the presentation, perhaps the information was there and I did not get it. Once an arrhythmia is identified, if it is a bradyarrhythmia, I imagine a pacemaker is probably in the works and perhaps for some of the tachyarrhythmias as well. Considering the impact of arrhythmias on adverse outcome development, are you implanting pacemaker leads at the time of the Fontan to use them should arrhythmias develop or do you just do the procedure later on if the arrhythmia develops?

My other question pertains to your recommendation for ablation. How do you manage that if, as I saw in your slide, most of the Fontan operations that are being done now are extracardiac, limiting access to the atria?

Dr d'Udekem. I'm not aware of any extracardiac conduit Fontan procedure that needed and had an ablation in Australia and New Zealand. Like you, we're wondering what we're going to do when the time comes, and we don't know yet. There is nobody in Australia and New Zealand who would put pacemaker leads in advance just in the case that they will be needed later. It may have been done, but it would be anecdotal.

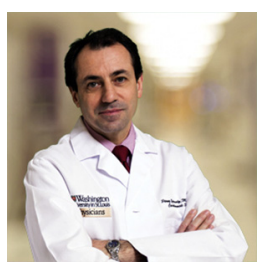

Dr P. Eghtesady (St Louis, Mo). Regarding the data, the time to the first onset of the tachyarrhythmias, was it approximately 10 to 11 years, is that correct, or did I get that incorrectly, the first episode?

Dr d'Udekem. So we look at it as a time-related event? Dr Eghtesady. From the time of the Fontan. 
Dr Carins. We didn't actually present those data today. We have calculated the median onset from tachyarrhythmias after the Fontan operation. I think from memory it's approximately 10 years.

Dr Backer. Was that the same for the lateral tunnel and extracardiac?

Dr d'Udekem. In a time-related event, it was the same for the lateral tunnel and the extracardiac. The atriopulmonary Fontan had a higher incidence.

Dr Eghtesady. So it's interesting. The reason I bring that up, or I ask it, is the presentation we got from CHOP, and sort of some of the data just looking at it, it's interesting you look at that data and at approximately 10 years is when you start seeing the curve starting to slip. It makes me wonder, is this tachyarrhythmia a sign, if you will, of the volume overload of that atrium from the collaterals, the burden of collaterals that develop over time, and essentially that's when you start slipping down the slippery slope. I find it coincidentally interesting that you guys in your cohort have seen it at approximately 10 to 11 years, because that's what I noticed on their graphs when they presented it.

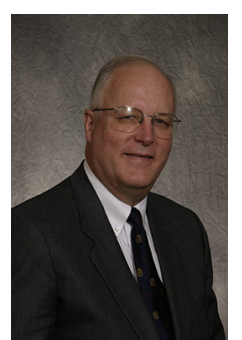

Dr J. Mayer, Jr (Boston, Mass). A few questions have occurred to me, and the first is whether or not the arrhythmia is the sign of ventricular dysfunction rather than it being necessarily the other way around? Do you have any data on what the ventricular function was at the time of onset of the first arrhythmia? Is there any difference at the same time interval after the Fontan between those patients who did and did not develop the arrhythmia at the same time interval after the Fontan?

Dr Carins. By looking at the echocardiogram reports, the majority of patients had subjectively good ventricular function before their arrhythmias, then developed their arrhythmia, and then had decreased ventricular function, although it is subjective.

Dr Mayer. The question really is what is the chicken and what's the egg, right? If the ventricular function is deteriorating and then there is an arrhythmia, then the arrhythmia is a manifestation of the ventricular dysfunction. Part of my thinking is influenced by our electrophysiologists at Children's who all say that they are the final common pathway for all failed congenital heart disease repairs. Therefore, I am curious what your thoughts or observations might be.

Dr d'Udekem. It's an interesting question. When I listened to the talk yesterday, Dr Rychik was explaining the mechanism of failure in Fontans, and we talk about pump failure. I think the evidence that these Fontan cases have, strictly speaking, a pump failure, a myocardial dysfunction with time, is very weak. When you perform transplantations in them, they have quite a bit of muscle there, it's contracting well, and when you look at the time lapse for them to develop ventricular dysfunction after the onset of arrhythmia, it's quite slow again. It takes a long time for them to develop ventricular dysfunction. But when they have ventricular dysfunction, my personal experience from looking at files is that they're going down clinically very quickly. So I don't think there is a lot of unmasked ventricular dysfunction in these patients.

Dr Mayer. The other aspect of ventricular function that we cannot measure well is diastolic function, and that may be more related to arrhythmia onset than necessarily systolic dysfunction.

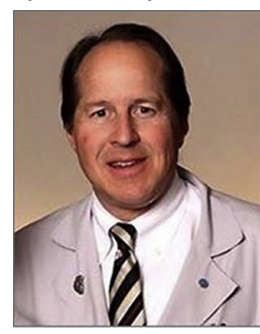

Dr C. Backer (Chicago, Ill). Yves, before you leave I want to pin you down a bit on your indications for Fontan conversion in the atriopulmonary Fontan cases. I believe you presented an article at the European meeting that discussed earlier referral having better outcomes. When you looked at your different centers, the ones that had a strategy of earlier conversion had better outcomes than those with a strategy of later conversion. Are you changing your views a bit on the basis of these data? Are you still recommending referring within 3 years of developing an arrhythmia, while the patients are still New York Heart Association II and before starting a second antiarrhythmic medication?

Dr d'Udekem. I'll secretly reveal some data that I just had last week. I had another student working on the atriopulmonary Fontans. We have different geographic eras, one that is doing early Fontan conversion and the rest are doing late Fontan conversions. If you have an atriopulmonary connection, because now we've been able to compare with the whole population of atriopulmonary Fontan cases, if you have a conversion in the geographic era where you have an early conversion, you have twice the chance of surviving than if you don't have a Fontan conversion. If you're in the geographic era where you do late conversions, if you have a Fontan conversion, you have 5 times the chance of dying or needing a heart transplantation compared with another atriopulmonary connection. So I think with that article and research, we'll bring strong evidence that you have a window of opportunity to do the Fontan conversion, and if you miss it, actually, you shouldn't do it because you're going to do them more harm than good.

Dr Backer. That's an important point. The window of opportunity. I think the other point is to have it done at a center such as yours that has the experience and expertise with the Fontan conversion procedure. The problem now may be that it is becoming too late for early referral because most of those patients who underwent an atriopulmonary connection have died, had a heart transplant, or, as you point out, it is now too late to refer them.

Dr d'Udekem. The clock is ticking. So if you have some of them, just work on them, I think. 


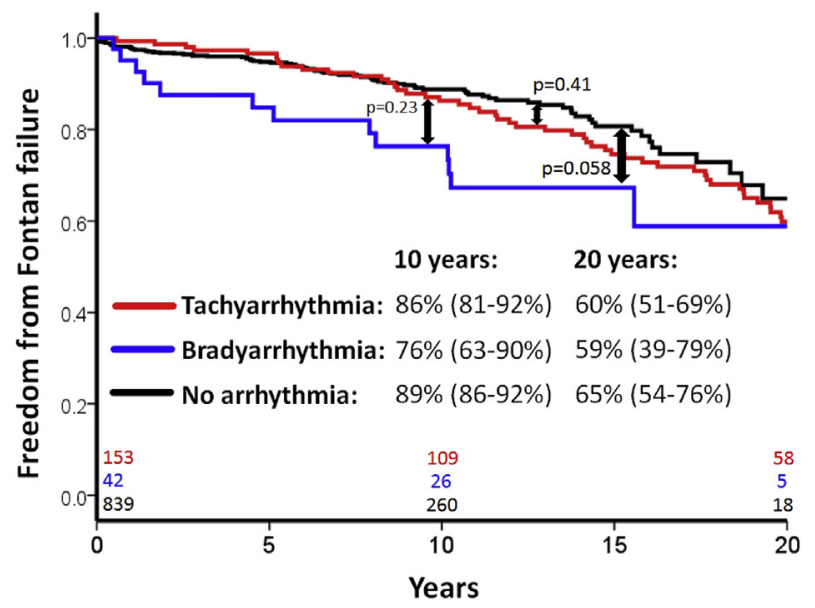

FIGURE E1. Freedom from Fontan failure from the time of Fontan procedure stratified by type of first encountered arrhythmia.

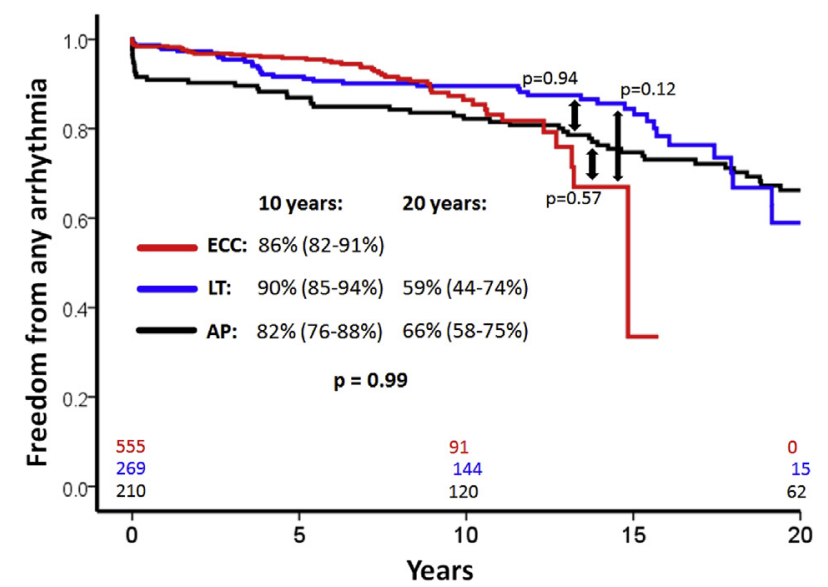

FIGURE E2. Freedom from development of any arrhythmia stratified by type of initial Fontan procedure. $E C C$, Extracardiac conduit; $L T$, lateral tunnel; $A P$, atriopulmonary.
TABLE E1. Independent predictors of late events after the Fontan procedure: Arrhythmia was inserted into regression models as a time-varying covariate

\begin{tabular}{|c|c|c|c|c|}
\hline Variable & HR & 95\% CI lower & 95\% CI upper & $P$ value \\
\hline \multicolumn{5}{|l|}{ Death } \\
\hline Any arrhythmia & 1.53 & 0.85 & 2.76 & .16 \\
\hline Male & 1.38 & 1.08 & 1.77 & .01 \\
\hline Age $>7$ y (vs 3-5 y) & 1.92 & 1.03 & 3.56 & .039 \\
\hline \multicolumn{5}{|l|}{ Death/transplantation } \\
\hline Any arrhythmia & 1.87 & 1.02 & 3.45 & .043 \\
\hline Male & 1.34 & 1.07 & 1.68 & .011 \\
\hline HLHS & 2.65 & 1.00 & 6.99 & .049 \\
\hline Age $>7$ y (vs 3-5 y) & 1.96 & 1.13 & 3.41 & .017 \\
\hline \multicolumn{5}{|l|}{ Fontan failure } \\
\hline Any arrhythmia & 1.85 & 1.16 & 2.95 & .010 \\
\hline Prior PA banding & 1.53 & 1.06 & 2.21 & .023 \\
\hline HLHS & 2.34 & 1.11 & 4.90 & .025 \\
\hline Age $>7$ y $($ vs $3-5$ y) & 1.75 & 1.16 & 2.64 & .008 \\
\hline
\end{tabular}

